\title{
Review Article \\ Potential Biomarkers of Fat Loss as a Feature of Cancer Cachexia
}

\author{
Maryam Ebadi and Vera C. Mazurak \\ Division of Human Nutrition, Department of Agricultural, Food and Nutritional Science, University of Alberta,
} 4-002 Li Ka Shing Centre for Health Research Innovation, Edmonton, AB, Canada T6G 2E1

Correspondence should be addressed to Vera C. Mazurak; vmazurak@ualberta.ca

Received 15 January 2015; Revised 17 April 2015; Accepted 18 April 2015

Academic Editor: Alessandro Laviano

Copyright (C) 2015 M. Ebadi and V. C. Mazurak. This is an open access article distributed under the Creative Commons Attribution License, which permits unrestricted use, distribution, and reproduction in any medium, provided the original work is properly cited.

\begin{abstract}
Fat loss is associated with shorter survival and reduced quality of life in cancer patients. Effective intervention for fat loss in cachexia requires identification of the condition using prognostic biomarkers for early detection and prevention of further depletion. No biomarkers of fat mass alterations have been defined for application to the neoplastic state. Several inflammatory cytokines have been implicated in mediating fat loss associated with cachexia; however, plasma levels may not relate to adipose atrophy. Zinc- $\alpha 2-$ glycoprotein may be a local catabolic mediator within adipose tissue rather than serving as a plasma biomarker of fat loss. Plasma glycerol and leptin associate with adipose tissue atrophy and mass, respectively; however, no study has evaluated their potential as a prognostic biomarker of cachexia-associated fat loss. This review confirms the need for further studies to identify valid prognostic biomarkers to identify loss of fat based on changes in plasma levels of biomarkers.
\end{abstract}

\section{Introduction}

Cancer cachexia is associated with increased mortality and morbidity in cancer patients [1]. By international consensus, cancer cachexia is proposed to be "a multifactorial syndrome defined by an ongoing loss of skeletal muscle mass with or without loss of fat mass that cannot be fully reversed by conventional nutritional support and leads to progressive functional impairment" [2]. A recent review [3] reported elevated lipolysis to be the major reason for fat loss in cancer cachexia $[4,5]$ although the underlying mechanisms are undefined. As cancer progresses, the majority of patients experience loss of fat. Fat loss precedes muscle loss, associates with shorter survival $[6,7]$, and is variable with respect to timing and intensity in various cancer populations [3]. Therefore, identification and validation of markers of fat loss are crucial not only for a better understanding of mechanisms, but also to identify fat losing cancer patients who will subsequently develop cachexia. Effective management of cancer cachexia is restricted to early identification of the syndrome; therefore, biomarkers are vital for development of appropriate therapeutic interventions to achieve better outcomes for individual cancer patients.
Adipose tissue (AT) is an active secretory organ, composed mainly of adipocytes and nonadipocyte cells such as inflammatory cells, immune cells, preadipocytes, and fibroblasts [8]. Adipokines are proteins synthesized and secreted from adipocytes which act both locally and distally, contributing to whole body lipid metabolism $[9,10]$. In pathophysiological conditions like cancer, macrophage infiltration into AT increases $[11,12]$, leading to alterations in adipokine production affecting adipose tissue mass and function. Local adipokines produced by AT, circulating cytokines, and lipid mobilizing factors are collectively involved in adipose atrophy in cancer cachexia $[13,14]$. Considering adipose tissue as a metabolically active organ as well as the relationship between fat loss and shorter survival in cancer, early identification of fat losing patients may increase the opportunity for therapeutic management of cachexia.

Biomarkers can be applied to represent tissue alterations under both physiological and pathological conditions [15]. A biomarker is "a biological molecule found in blood, other body fluids, or tissues that is a sign of a normal or abnormal process or of a condition or disease." [16]. Biomarkers indicate normal biologic processes, pathogenic processes, or pharmacological responses to a treatment [15]. 
Biomarkers in the oncology setting, identified using highthroughput sequencing, gene expression arrays, and mass spectroscopy [17], are classified into prognostic, predictive, and pharmacodynamic categories [18-20]. Prognostic biomarkers provide information about likely outcome of a disease, regardless of treatment, whilst predictive biomarkers assess the effect of a particular treatment. Pharmacodynamic biomarkers assess drug treatment effects on a tumour [1820]. Ideal biomarkers are easily accessible, available, specific and sensitive, noninvasive, inexpensive, consistent, safe, and easy quantifiable in a biological fluid or clinical sample. Biomarkers are consistent across genders and ethnic groups. Levels of the biomarker should not overlap between controls and patients while significantly relating to the outcome of interest using appropriate statistical analysis [18].

While it seems important to identify a prognostic biomarker of cancer cachexia-associated fat loss, no ideal clinical biomarker has been defined yet, which demonstrates a need to identify and subsequently validate potential biomarkers in independent studies. Studies focusing on adipose tissue have identified leptin, free fatty acids (FFAs), and glycerol in plasma as indicators of fat alterations in health and diseases. On the other hand, adipokines including inflammatory cytokines such as interleukin-6 (IL-6) and tumour necrosis factor- $\alpha$ (TNF- $\alpha$ ) [21] as well as Zinc- $\alpha 2$ glycoprotein (ZAG) [22] have also been associated with weight and fat loss in cancer. Therefore, circulating levels of these factors may represent new noninvasive prognostic biomarker of adipose atrophy and targets in the detection and management of fat loss in cancer.

One of the major obstacles to identify reliable biomarkers of fat loss in cancer cachexia is variation between studies in how fat loss is assessed. Body mass index (BMI) is frequently used as a clinically accessible measure of human body composition. However, as BMI does not distinguish between fat and fat-free mass, its utility in the settings of fat loss in cancer cachexia is limited [23]. Various methods including bioelectrical impedance analysis (BIA), dual-energy Xray absorptiometry (DEXA), magnetic resonance imaging (MRI), and computed tomography (CT) scan analysis [24] have been applied to assess body composition in cancer population. CT image analysis, as the gold standard for body composition assessment in cancer patients, has an ability to discriminate and precisely quantify different adipose tissue depots. Many patients have repeated scans over the cancer trajectory enabling assessments in the same individual over time. Application of body composition assessment in the cancer setting has focussed primarily on lean body mass. The studies that do exist reveal loss of adipose tissue as cancer progress $[25,26]$. However, further studies are required to establish the timeline and pattern of fat mass alterations in different adipose tissue depots during cancer progression [3]. Moreover, the majority of studies assessing fat mass focus on gastrointestinal cancer patients; there remains a gap in knowledge related to other malignant tumours. Finally, timing of CT scans differs between patients and scans may not be available over a specific time points demonstrating the need for other important prognostic biomarkers of fat loss. Overall, gaps remain related to the association between fat mass alterations assessed by CT scans and circulating markers of fat loss. This article reviews current knowledge around potential prognostic biomarkers of fat loss in cancer which may identify fat-losing cancer patients who would benefit from early therapeutic interventions to improve outcome of cancer patients. Possibilities and potential to apply these markers as prognostic biomarkers of fat loss will be discussed.

\section{Inflammatory Cytokines}

Serum levels of cytokines associate with clinical features of cancer cachexia such as weight loss; however, no study has specifically assessed the association between serum cytokines and the extent of fat loss in cancer patients. Inflammatory cytokines, such as IL- 6 and TNF- $\alpha$, are produced by tumours and by nonfat cells residing in AT [21] in addition to adipocytes. Plasma levels of inflammatory cytokines are elevated in cachexia [27] and are thought to promote adipose atrophy in animal and human models of cachexia [13]. Pathways of adipose tissue metabolism evoked by IL- 6 and TNF$\alpha$ include inhibition of lipoprotein lipase mRNA expression and activity which prevents fat cells from taking up fatty acids from lipoproteins $[28,29]$. These cytokines stimulate hormone sensitive lipase (HSL) and adipose triglyceride lipase (ATGL) activity [30, 31], leading to elevated lipolysis. TNF$\alpha$ has been reported to prevent preadipocyte differentiation [32] and inhibit expression of lipogenic transcription factors [33]. Collectively, these alterations would result in fat loss.

Serum TNF- $\alpha$ levels negatively correlate with body weight and BMI in pancreatic cancer patients [34]. Tumour presence has been associated with elevated serum IL-6 and TNF- $\alpha$ in mice bearing the Lewis lung carcinoma or B16 melanoma cells compared to controls [35]. In humans, data regarding the role of TNF- $\alpha$ in cancer-associated wasting are controversial. Measuring TNF- $\alpha$ in plasma is challenging due to short half-life and transient nature. Further, the sensitivity of assays used to measure plasma TNF- $\alpha$ is variable, making comparisons between studies limited [36]. On the other hand, TNF-R1 and TNF-R2 (soluble TNF- $\alpha$ membrane receptors) have been applied as serum markers of TNF- $\alpha$ activity due to their longer half-life and greater stability [37].

A comprehensive review of clinical factors associated with cachexia [38] showed little evidence for the association between serum TNF- $\alpha$ and weight loss in cancer, while several studies report an association of plasma IL-6 but not TNF- $\alpha$ with cachexia-associated wasting rather than cancer per se. Serum IL-6 levels were higher in fat losing gastrointestinal cachectic cancer patients compared to weight stable and noncancer controls. However, no changes in mRNA expression or secretion of IL- 6 and TNF- $\alpha$ from SAT were observed [4]. This finding was confirmed in another study showing that circulating IL-6 levels were higher in weight losing non-small-cell lung carcinoma patients compared to weight stable cancer patients [39].

Adipose atrophy has been associated with elevated IL6 signalling in a preclinical model of cancer cachexia [40]. In patients with gastrointestinal cancer, plasma IL-6 levels significantly correlated with the presence of tumour and 
increased with each progressive stage of cancer [41]. IL-6 has been reported to be involved in early stages of cachexia $[42,43]$ and a study conducted in patients with mixed tumor types showed IL-6 levels gradually increased during early stages of cachexia followed by rapid increase prior to death [44]. In contrast, a study in 61 patients with advanced cancer showed no correlation between IL- 6 , TNF- $\alpha$, and weight loss [45]. Although circulating IL-6 levels were higher in cachectic mice compared to controls [46], IL-6 receptors deficient (IL6-R-KO) mice were partially protected so other cytokines may involve in cachexia-associated wasting. Moreover, a study published in 2012 reported that other cytokines, such as IL- $1 \beta$ but not IL- 6 , may be better indicator of cachexia features such as weight loss and body composition alterations [43].

Collectively, evidence would suggest that inflammatory cytokines are involved in AT depletion in cancer [13, 36, 42]; however, plasma concentrations may represent the presence of a tumour rather than cachexia-associated adipose atrophy per se [41]. Future studies are required to assess changes in adipose tissue depots, both visceral adipose tissue (VAT) and subcutaneous adipose tissue (SAT) over the disease trajectory using validated body composition assessment tools and correlating those to changes in circulating cytokines. Given that there could be various sources of cytokines contributing to plasma levels, the transient nature of cytokines, as well as the cost associated with cytokine measures, the application of plasma measures of cytokines as biomarkers of adipose tissue atrophy in the clinical study is likely limited. Moreover, the ability of cytokines to evoke cancer cachexia depends on tumour type and the complex response within a network of mediators, rather than a single cytokine $[47,48]$. Major gaps remain regarding the association between plasma cytokine levels and fat loss, clinical ranges of abnormal measures, and method sensitivity.

\section{Leptin}

Leptin is an adipokine, produced mainly by adipocytes [49]. Leptin regulates body weight by activating the anorexigenic neuropeptides and inhibiting the orexigenic neurons such neuropeptide Y (NPY) [50, 51]. Besides body weight and fat mass regulation, leptin is involved in immune function and inflammation [52]. Normally, a lower plasma concentration of leptin is associated with higher NPY secretion; however, NPY pathways have been reported to be dysfunctional in anorectic tumour-bearing rats [53]. Many factors influence leptin synthesis and secretion in adipocytes such as insulin, TNF- $\alpha$, glucocorticoids, reproductive hormones, and prostaglandins [54, 55]. In humans, the main factor influencing plasma leptin concentration is adipose tissue mass.

A higher concentration of serum leptin in obese individuals is associated with increased fat mass and cell size [10]. Serum leptin is considered to be an accurate, reliable, and highly correlated measure of total body fat [56]. In healthy subjects [57], elderly adults [58], and obesity [52], plasma leptin levels have been shown to be a precise measure of adiposity. A relationship between low fat mass and low plasma leptin levels has also been reported in cancer patients [59-67]. Advanced gastrointestinal and lung cancer patients experiencing cachexia-associated adipose atrophy exhibited hypoleptinemia [67-69]. On the other hand, breast and gynaecological cancer patients exhibited elevated plasma leptin levels that related to the elevated levels of sex hormones and receptors, rather than cachexia per se [70].

Circulating leptin concentrations have been used as an indicator of fat mass; however further studies are required to examine changes in leptin concentrations that occur throughout the disease trajectory and relative to body fat mass alterations. Longitudinal studies that employ a precise measure of body fat would enable determination of whether changes in plasma levels of leptin change proportional to fat mass alterations. An added level of complexity is that leptin is secreted by both VAT and SAT, with SAT contributing the majority of leptin to plasma due to its larger contribution to overall body mass [65]. Therefore, measures of changes in leptin concentrations over time do not currently represent the type of fat being lost or gained.

Comparison between studies is limited by different assay sensitivities and how leptin values are reported as total, free, or bound leptin. Further, factors such as the type of cancer, BMI, and sex and age influence serum leptin concentration, as reported in adolescents [71], also need to be considered in study interpretation. Low leptin concentrations could be considered a result, not a cause of cachexia, which significantly relates to adipose atrophy and low fat mass in cachexia.

\section{Plasma Glycerol}

Studies indicate elevated lipolysis to be the main cause of fat loss in cancer $[4,5,72-75]$. During AT lipolysis, FFAs and glycerol molecules are produced by the action of lipolytic enzymes such as ATGL and HSL, which hydrolyze stored triglyceride [30]. Adipose atrophy has been associated with elevated activity of ATGL and HSL in human and animal models of cancer [35, 40, 46]. Elevated lipolysis produces higher plasma glycerol in cachectic cancer patients compared to healthy subjects [74] or weight-stable controls [5]. Lipolytic activity was assessed in 13 cachectic and 14 weightstable cancer patients by assessing circulating glycerol levels ( $\mu \mathrm{mol} / \mathrm{L} / \mathrm{Kg}$ body fat) as an indicator of in vivo lipolysis. Cachexia was defined as $>5 \%$ weight loss over 3 months or $>10 \%$ within the previous 6 months. Body fat mass, assessed using BIA, showed lower body fat (\% and $\mathrm{kg}$ ) in the cachectic group compared to weight stable patients. Elevated levels of plasma glycerol, FFAs, and higher expression of genes involved in energy turnover pathways and oxidative phosphorylation revealed increased lipid mobilization from subcutaneous adipose tissue in the cachectic group [72]. These results support those of Agustsson et al. [76] who showed plasma glycerol and FFAs to be higher in newly diagnosed gastrointestinal cancer patients with cachexia who had low body fat mass $(\mathrm{kg})$, assessed using CT images, compared to the weight-stable group. Higher plasma glycerol and FFAs in the cachectic group positively correlated with 
percent weight loss and negatively correlated with visceral adipose tissue area [76].

Plasma glycerol values in cancer cachectic patients have been reported as $\mu \mathrm{mol} / \mathrm{L}$ [77] or $\mu \mathrm{mol} / \mathrm{L} / \mathrm{Kg}$ body fat $[4,5$, $72,76]$. Interestingly, studies focusing on lipolytic activity in cancer cachexia report a narrow range of plasma glycerol for cachectic patients between studies $[4,5,72,76]$, strengthening its use a potential biomarker. Plasma glycerol has been reported as $6.2 \pm 2.7$ [5], $6.9 \pm 1.3$ [76], $7.0 \pm 4.3$ [72] , and 9.8 $\pm 2[4](\mu \mathrm{mol} / \mathrm{L} / \mathrm{Kg}$ body fat $)$ in cachectic patients compared to weight stable cancer patients reported at $3.1 \pm 0.7$ [5], $3.9 \pm$ 0.6 [76], $3.4 \pm 1.6$ [72], and $3.3 \pm 0.3$ [4] ( $\mu \mathrm{mol} / \mathrm{L} / \mathrm{Kg}$ body fat). Postabsorptive whole body lipolytic rate, assessed by glycerol infusion technique, revealed basal levels of plasma glycerol to be higher in a cancer group compared to controls. While lipolytic rates were similar, glycerol clearance rate varied between the two groups and contributed to higher glycerol levels. Although preillness weight loss ranged from 0 to $20 \%$ in cancer patients, the same results were obtained when data was corrected for body weight [78].

Despite the use of plasma glycerol as an index of wholebody lipolysis, caution should be exercised when considering the results of these studies. Lipolysis results in the release of fatty acids and glycerol from adipose tissue, with glycerol being a better index of lipolysis as FFAs liberated by lipolysis may be reesterified within adipose tissue [79]. AT has very low glycerol kinase activity [80], and glycerol released by lipolysis enters into the bloodstream. However, lipolytic activity is not specific to adipose tissue and occurs also from intermuscular triglyceride stores and plasma lipoproteins [79]. Glycerol concentration may indicate that lipolysis occurs in SAT as glycerol released from visceral adipose tissue lipolysis enters the liver via the portal vein [81]. Therefore, plasma concentrations of glycerol reflect the balance between glycerol release by lipolysis (predominantly adipose tissue) and clearance of glycerol by liver [79] and should be interpreted with caution.

\section{Zinc- $\alpha 2$-glycoprotein}

ZAG is a protein discovered in human plasma [82] that has been associated with presence of several types of carcinomas such as breast, prostate, and lung [83-85]. Elevated serum ZAG, as a routine and reliable measurement, may apply to early diagnosis of cachectic cancer patients with adipose atrophy [86]. ZAG has been considered as an adipokine involved in lipid metabolism in adipose tissue $[87,88]$. Both in vivo and in vitro studies have shown that increased ZAG expression in adipose tissue is associated with increased lipolysis and subsequent fat and weight loss $[89,90]$. The exact mechanism by which ZAG participates in fat loss in cancer is not known. ZAG may induce lipolysis through activation of $\beta$-adrenoreceptors $[89,91]$ and elevated HSL activity [92, 93]. Although the mechanism behind ZAG regulation in AT is still unknown, glucocorticoids have been suggested to stimulate ZAG expression in AT [94]. Increased plasma cortisol levels in cachectic tumor bearing mice [93] and in cancer patients [95] have been associated with higher AT ZAG expression and elevated lipolysis. This implies that, in cachexia, glucocorticoids may induce lipolytic activity through an increase in ZAG expression $[94,96]$.

There is discrepancy in the association between circulating ZAG levels and weight or fat loss in various conditions. Data on serum ZAG levels in obesity are inconsistent, being reported as either increased [97] or decreased [98] which positively and negatively correlated, respectively, with BMI. Elevated serum ZAG levels have been observed in chronic heart failure and haemodialysis patients suggesting ZAG to be a marker of fat catabolism [22]. In contrast, two studies in cancer patients $[77,92]$ demonstrated that plasma ZAG levels may not be a good biomarker of cachexia-associated features such as weight and fat loss. Twenty-five GI cancer patients underwent curative abdominal surgery and were categorized as cachectic or weight stable. Cachexia was defined as unintentional weight loss of more than $5 \%$ during the previous 6 months. mRNA and protein levels of ZAG in subcutaneous adipose tissue were higher in cachectic cancer patients compared to weight-stable cancer patients which significantly correlated with fasting serum glycerol levels and weight loss. In this study, however, there was no significant difference in circulating ZAG levels between cachectic and weight stable cancer patients. Production of ZAG by tumours and nonadipose tissue, such as the liver, may also affect ZAG plasma levels [92]. This result is consistent with Rydén et al. [77] who report that ZAG is a locally produced factor, promoting AT lipolysis, but not secreted predominately to circulation [77]. Therefore, circulating levels of ZAG are not likely to relate to fat loss in cancer cachectic patients but instead may mediate local lipid mobilising action in adipose tissue.

\section{Conclusion}

Patients with advanced cancer frequently suffer weight and fat loss. Accelerated loss of adipose tissue is associated with shorter survival, reduced quality of life, and decreased muscle mass during cancer progression [6]. Due to the role of adipose tissue in mediating human metabolism, identification of prognostic biomarkers of fat loss in cancer may help to identify fat losing cancer patients for early therapeutic interventions, improved survival, and prevention of muscle atrophy in cancer patients.

No studies in cancer have identified a prognostic biomarker of fat mass alterations nor have the sensitivity, specificity, and reproducibility of potential indicators been assessed in the neoplastic state. Inconsistency in the literature may be due to varying sensitivity of assays used to measure plasma levels of mediators, heterogeneity of patient populations and treatment, and various body composition assessment methods. Inflammatory cytokines appear to be mediators of cachexia-associated features such as fat loss $[13,36,42]$; however, they do not fulfill several components of biomarker criteria. Relationship between circulating cytokines and degree of fat loss in cancer has not been assessed. ZAG in plasma has been suggested to indicate the presence of some type of tumours, and in AT, ZAG can act locally to modulate lipolysis. Literature regarding the potential of plasma ZAG to be a biomarker of fat loss during 
the development of cancer cachexia is inconsistent. Enhanced adipose tissue ZAG expression in cancer cachexia suggests that ZAG could be a local catabolic mediator within the tissue rather than being a biomarker of fat loss [77]. Therefore, the ability of ZAG to be applied as a marker of lipid utilization in cachexia syndrome and to indirectly represent fat loss is limited.

Plasma glycerol and leptin may have potential to be considered as biomarkers of lipolysis and fat mass, respectively; however, no study has defined a confirmed range and optimal cut-off points for these markers. It is not clear whether a single biomarker or combination may have the most prognostic value, as no study has assessed various combinations in a cancer population. Measuring changes in fat mass over time concurrent with circulating levels of biomarkers of fat mass would provide valuable information about application of proposed fat loss biomarkers throughout the disease trajectory. These studies would help establish valid criteria to identify loss of whole body fat mass based on changes in plasma levels of these specific biomarkers.

Alterations in fat mass and composition between visceral and subcutaneous depots are divergent and vary over the cancer trajectory. The proportional reduction of each fat depot may be a consideration when establishing biomarkers. For example, it remains to be determined whether decreased leptin levels indicate the loss of visceral or subcutaneous adipose tissue in cancer. Future studies should consider the metabolic differences between these depots in determining specific biomarkers.

Although many of the proposed biomarkers are economical, easy, and quick to quantify in plasma, further steps such as comparison of plasma levels in healthy, weight stable, and weight losing cancer patients as well as their correlation with various degrees of fat loss assessed by CT images should be considered in determining capacity for application of a prognostic biomarker of fat loss in cancer. Proper study design, combined with extensive testing, and quantitative measurement of large numbers of proteins in body fluids using advanced techniques [99] as well as statistical validation of prognostic biomarkers [100] are important factors in identification of fat loss biomarkers. This review confirms the need for further studies to (1) assess how alterations in fat mass is reflected in measurable biomarkers, (2) minimize variations that may confound establishment of a biomarker, and (3) increase specificity and sensitivity of methods to detect biomarkers in samples at minimum levels or in repeated measures.

\section{Conflict of Interests}

The authors declare that there is no conflict of interests regarding the publication of this paper.

\section{References}

[1] M. J. Tisdale, "Cachexia in cancer patients," Nature Reviews Cancer, vol. 2, no. 11, pp. 862-871, 2002.

[2] K. Fearon, F. Strasser, S. D. Anker et al., "Definition and classification of cancer cachexia: an international consensus," The Lancet Oncology, vol. 12, no. 5, pp. 489-495, 2011.
[3] M. Ebadi and V. C. Mazurak, "Evidence and mechanisms of fat depletion in cancer," Nutrients, vol. 6, pp. 5280-5297, 2014.

[4] M. Rydén, T. Agustsson, J. Laurencikiene et al., "Lipolysis-not inflammation, cell death, or lipogenesis-is involved in adipose tissue loss in cancer cachexia," Cancer, vol. 113, no. 7, pp. 16951704, 2008.

[5] T. Agustsson, M. Rydén, J. Hoffstedt et al., "Mechanism of increased lipolysis in cancer cachexia," Cancer Research, vol. 67, no. 11, pp. 5531-5537, 2007.

[6] R. A. Murphy, M. S. Wilke, M. Perrine et al., "Loss of adipose tissue and plasma phospholipids: relationship to survival in advanced cancer patients," Clinical Nutrition, vol. 29, no. 4, pp. 482-487, 2010.

[7] M. Fouladiun, U. Körner, I. Bosaeus, P. Daneryd, A. Hyltander, and K. G. Lundholm, "Body composition and time course changes in regional distribution of fat and lean tissue in unselected cancer patients on palliative care-correlations with food intake, metabolism, exercise capacity, and hormones," Cancer, vol. 103, no. 10, pp. 2189-2198, 2005.

[8] M. M. Ibrahim, "Subcutaneous and visceral adipose tissue: structural and functional differences," Obesity Reviews, vol. 11, no. 1, pp. 11-18, 2010.

[9] P. Trayhurn and I. S. Wood, "Adipokines: inflammation and the pleiotropic role of white adipose tissue," British Journal of Nutrition, vol. 92, no. 3, pp. 347-355, 2004.

[10] T. Ronti, G. Lupattelli, and E. Mannarino, "The endocrine function of adipose tissue: an update," Clinical Endocrinology, vol. 64, no. 4, pp. 355-365, 2006.

[11] T. H. Mayi, M. Daoudi, B. Derudas et al., "Human adipose tissue macrophages display activation of cancer-related pathways," The Journal of Biological Chemistry, vol. 287, no. 26, pp. 2190421913, 2012.

[12] S. P. Weisberg, D. McCann, M. Desai, M. Rosenbaum, R. L. Leibel, and A. W. Ferrante Jr., "Obesity is associated with macrophage accumulation in adipose tissue," Journal of Clinical Investigation, vol. 112, no. 12, pp. 1796-1808, 2003.

[13] C. Bing, "Lipid mobilization in cachexia: mechanisms and mediators," Current Opinion in Supportive and Palliative Care, vol. 5, no. 4, pp. 356-360, 2011.

[14] M. L. Batista, S. B. Peres, M. E. McDonald et al., "Adipose tissue inflammation and cancer cachexia: possible role of nuclear transcription factors," Cytokine, vol. 57, no. 1, pp. 9-16, 2012.

[15] K. Strimbu and J. A. Tavel, "What are biomarkers?" Current Opinion in HIV and AIDS, vol. 5, no. 6, pp. 463-466, 2010.

[16] Dictionary of Cancer Terms, National Cancer Institute, http://www.Cancer.gov/dictionary/?searchTxt=biomarker.

[17] J. D. Brooks, "Translational genomics: the challenge of developing cancer biomarkers," Genome Research, vol. 22, no. 2, pp. 183-187, 2012.

[18] C. O. Madu and Y. Lu, "Novel diagnostic biomarkers for prostate cancer," Journal of Cancer, vol. 1, no. 1, pp. 150-177, 2010.

[19] E. Drucker and K. Krapfenbauer, "Pitfalls and limitations in translation from biomarker discovery to clinical utility in predictive and personalised medicine," EPMA Journal, vol. 4, no. 1, article 7, 2013.

[20] C. N. A. M. Oldenhuis, S. F. Oosting, J. A. Gietema, and E. G. E. de Vries, "Prognostic versus predictive value of biomarkers in oncology," European Journal of Cancer, vol. 44, no. 7, pp. 946953, 2008.

[21] K. C. H. Fearon, D. J. Glass, and D. C. Guttridge, "Cancer cachexia: mediators, signaling, and metabolic pathways," Cell Metabolism, vol. 16, no. 2, pp. 153-166, 2012. 
[22] A. Cabassi and S. Tedeschi, "Zinc- $\alpha 2$-glycoprotein as a marker of fat catabolism in humans," Current Opinion in Clinical Nutrition and Metabolic Care, vol. 16, no. 3, pp. 267-271, 2013.

[23] M. J. Garcia-Oria Serrano, M. Armengol Carrasco, A. Caballero Millán, C. D. Ching, and A. Codina Cazador, "Is Body Mass Index a prognostic factor of survival in colonic cancer? A multivariate analysis," Cirugia Espanola, vol. 89, no. 3, pp. 152158, 2011.

[24] E. D. Fabbro, V. Baracos, W. Demark-Wahnefried, T. Bowling, J. Hopkinson, and E. Bruera, Eds., Nutrition and the Cancer Patient, Oxford University Press, New York, NY, USA, 2010.

[25] C. M. Prado, M. B. Sawyer, S. Ghosh et al., "Central tenet of cancer cachexia therapy: do patients with advanced cancer have exploitable anabolic potential?" American Journal of Clinical Nutrition, vol. 98, no. 4, pp. 1012-1019, 2013.

[26] J. R. Lieffers, M. Mourtzakis, K. D. Hall, L. J. McCargar, C. M. M. Prado, and V. E. Baracos, "A viscerally driven cachexia syndrome in patients with advanced colorectal cancer: contributions of organ and tumor mass to whole-body energy demands," American Journal of Clinical Nutrition, vol. 89, no. 4, pp. 1173-1179, 2009.

[27] B. H. L. Tan, D. A. C. Deans, R. J. E. Skipworth, J. A. Ross, and K. C. H. Fearon, "Biomarkers for cancer cachexia: is there also a genetic component to cachexia?" Supportive Care in Cancer, vol. 16, no. 3, pp. 229-234, 2008.

[28] M. Kawakami, T. Murase, H. Ogawa et al., "Human recombinant TNF suppresses lipoprotein lipase activity and stimulates lipolysis in 3T3-L1 cells," Journal of Biochemistry, vol. 101, no. 2, pp. 331-338, 1987.

[29] S. W. Coppack, "Pro-inflammatory cytokines and adipose tissue," Proceedings of the Nutrition Society, vol. 60, no. 3, pp. 349-356, 2001.

[30] X. Yang, X. Zhang, B. L. Heckmann, X. Lu, and J. Liu, "Relative contribution of adipose triglyceride lipase and hormonesensitive lipase to tumor necrosis factor- $\alpha$ (TNF- $\alpha$ )-induced lipolysis in adipocytes," The Journal of Biological Chemistry, vol. 286, no. 47, pp. 40477-40485, 2011.

[31] G. Van Hall, A. Steensberg, M. Sacchetti et al., "Interleukin6 stimulates lipolysis and fat oxidation in humans," Journal of Clinical Endocrinology and Metabolism, vol. 88, no. 7, pp. 30053010, 2003.

[32] B. Beutler, D. Greenwald, J. D. Hulmes et al., "Identity of tumour necrosis factor and the macrophage-secreted factor cachectin," Nature, vol. 316, no. 6028, pp. 552-554, 1985.

[33] W. P. Cawthorn and J. K. Sethi, "TNF- $\alpha$ and adipocyte biology," FEBS Letters, vol. 582, no. 1, pp. 117-131, 2008.

[34] A. J. Karayiannakis, K. N. Syrigos, A. Polychronidis, M. Pitiakoudis, A. Bounovas, and K. Simopoulos, "Serum levels of tumor necrosis factor-alpha and nutritional status in pancreatic cancer patients," Anticancer Research, vol. 21, no. 2, pp. 1355-1358, 2001.

[35] S. K. Das, S. Eder, S. Schauer et al., "Adipose triglyceride lipase contributes to cancer-associated cachexia," Science, vol. 333, no. 6039, pp. 233-238, 2011.

[36] S. K. Das and G. Hoefler, "The role of triglyceride lipases in cancer associated cachexia," Trends in Molecular Medicine, vol. 19, no. 5, pp. 292-301, 2013.

[37] K. Hosono, E. Yamada, H. Endo et al., "Increased tumor necrosis factor receptor 1 expression in human colorectal adenomas," World Journal of Gastroenterology, vol. 18, no. 38, pp. 5360-5368, 2012.
[38] D. Blum, A. Omlin, V. E. Baracos et al., "Cancer cachexia: a systematic literature review of items and domains associated with involuntary weight loss in cancer," Critical Reviews in Oncology/Hematology, vol. 80, no. 1, pp. 114-144, 2011.

[39] A. J. Staal-Van den Brekel, M. A. Dentener, A. M. W. J. Schols, W. A. Buurman, and E. F. M. Wouters, "Increased resting energy expenditure and weight loss are related to a systemic inflammatory response in lung cancer patients," Journal of Clinical Oncology, vol. 13, no. 10, pp. 2600-2605, 1995.

[40] M. Tsoli, M. Schweiger, A. S. Vanniasinghe et al., "Depletion of white adipose tissue in cancer cachexia syndrome is associated with inflammatory signaling and disrupted circadian regulation," PLoS ONE, vol. 9, no. 3, Article ID e92966, 2014.

[41] M. L. Batista Jr., M. Olivan, P. S. M. Alcantara et al., "Adipose tissue-derived factors as potential biomarkers in cachectic cancer patients," Cytokine, vol. 61, no. 2, pp. 532-539, 2013.

[42] M. J. Tisdale, "Mechanisms of cancer cachexia," Physiological Reviews, vol. 89, no. 2, pp. 381-410, 2009.

[43] C. Scheede-Bergdahl, H. L. Watt, B. Trutschnigg et al., "Is IL6 the best pro-inflammatory biomarker of clinical outcomes of cancer cachexia?" Clinical Nutrition, vol. 31, no. 1, pp. 85-88, 2012.

[44] S. Iwase, T. Murakami, Y. Saito, and K. Nakagawa, "Steep elevation of blood interleukin-6 (IL-6) associated only with late stages of cachexia in cancer patients," European Cytokine Network, vol. 15, no. 4, pp. 312-316, 2004.

[45] M. Maltoni, L. Fabbri, O. Nanni et al., "Serum levels of tumour necrosis factor alpha and other cytokines do not correlate with weight loss and anorexia in cancer patients," Supportive Care in Cancer, vol. 5, no. 2, pp. 130-135, 1997.

[46] M. Petruzzelli, M. Schweiger, R. Schreiber et al., "A switch from white to brown fat increases energy expenditure in cancerassociated cachexia," Cell Metabolism, vol. 20, no. 3, pp. 433-447, 2014.

[47] M. J. Tisdale, "Molecular pathways leading to cancer cachexia," Physiology, vol. 20, no. 5, pp. 340-348, 2005.

[48] J. M. Argilés, F. J. López-Soriano, and S. Busquets, "Counteracting inflammation: a promising therapy in cachexia," Critical Reviews in Oncogenesis, vol. 17, no. 3, pp. 253-262, 2012.

[49] G. Fantuzzi, "Adipose tissue, adipokines, and inflammation," Journal of Allergy and Clinical Immunology, vol. 115, no. 5, pp. 911-920, 2005.

[50] M. A. Cowley, J. L. Smart, M. Rubinstein et al., "Leptin activates anorexigenic POMC neurons through a neural network in the arcuate nucleus," Nature, vol. 411, no. 6836, pp. 480-484, 2001.

[51] T. L. Horvath, F. Naftolin, S. P. Kalra, and C. Leranth, "Neuropeptide-Y innervation of beta-endorphin-containing cells in the rat mediobasal hypothalamus: A light and electron microscopic double immunostaining analysis," Endocrinology, vol. 131, no. 5, pp. 2461-2467, 1992.

[52] N. R. Shah and E. R. Braverman, "Measuring adiposity in patients: the utility of body mass index (BMI), percent body fat, and leptin," PLoS ONE, vol. 7, no. 4, Article ID e33308, 2012.

[53] W. T. Chance, A. Balasubramaniam, J. E. Fischer, E. M. Copeland III, R. S. Jones, and K. I. Bland, "Neuropeptide Y and the development of cancer anorexia," Annals of Surgery, vol. 221, no. 5, pp. 579-589, 1995.

[54] M. Bulló, P. García-Lorda, I. Megias, and J. Salas-Salvadó, "Systemic inflammation, adipose tissue tumor necrosis factor, and leptin expression," Obesity Research, vol. 11, no. 4, pp. 525531, 2003. 
[55] C. D. Russell, M. R. Ricci, R. E. Brolin, E. Magill, and S. K. Fried, "Regulation of the leptin content of obese human adipose tissue," American Journal of Physiology-Endocrinology and Metabolism, vol. 280, no. 3, pp. E399-E404, 2001.

[56] R. V. Considine, M. K. Sinha, M. L. Heiman et al., "Serum immunoreactive-leptin concentrations in normal-weight and obese humans," The New England Journal of Medicine, vol. 334, no. 5, pp. 292-295, 1996.

[57] H. Shimizu, Y. Shimomura, R. Hayashi et al., "Serum leptin concentration is associated with total body fat mass, but not abdominal fat distribution," International Journal of Obesity, vol. 21, no. 7, pp. 536-541, 1997.

[58] C. E. Ruhl, T. B. Harris, J. Ding et al., "Body mass index and serum leptin concentration independently estimate percentage body fat in older adults," The American Journal of Clinical Nutrition, vol. 85, no. 4, pp. 1121-1126, 2007.

[59] A. Kowalczuk, A. Wiecek, E. Franek, and F. Kokot, "Plasma concentration of leptin, neuropeptide $\mathrm{Y}$ and tumor necrosis factor alpha in patients with cancers, before and after radio- and chemotherapy," Polskie Archiwum Medycyny Wewnetrznej, vol. 106, no. 2, pp. 657-668, 2001.

[60] B. Weryńska, M. Kosacka, M. Gołecki, and R. Jankowska, "Leptin serum levels in cachectic and non-cachectic lung cancer patients," Pneumonologia i Alergologia Polska, vol. 77, no. 6, pp. 500-505, 2009.

[61] J. Smiechowska, A. Utech, G. Taffet, T. Hayes, M. Marcelli, and J. M. Garcia, "Adipokines in patients with cancer anorexia and cachexia," Journal of Investigative Medicine, vol. 58, no. 3, pp. 554-559, 2010.

[62] H. Dülger, S. Alici, M. R. Şekeroǧlu et al., "Serum levels of leptin and proinflammatory cytokines in patients with gastrointestinal cancer," International Journal of Clinical Practice, vol. 58, no. 6, pp. 545-549, 2004.

[63] A. M. Wallace, N. Sattar, and D. C. McMillan, "Effect of weight loss and the inflammatory response on leptin concentrations in gastrointestinal cancer patients," Clinical Cancer Research, vol. 4, no. 12, pp. 2977-2979, 1998.

[64] G. Mantovani, A. Macciò, L. Mura et al., "Serum levels of leptin and proinflammatory cytokines in patients with advanced-stage cancer at different sites," Journal of Molecular Medicine, vol. 78, no. 10, pp. 554-561, 2000.

[65] A. G. W. Moses, N. Dowidar, B. Holloway, I. Waddell, K. C. H. Fearon, and J. A. Ross, "Leptin and its relation to weight loss, ob gene expression and the acute-phase response in surgical patients," British Journal of Surgery, vol. 88, no. 4, pp. 588-593, 2001.

[66] A. M. Wallace, A. Kelly, N. Sattar, C. S. McArdle, and D. C. McMillan, "Circulating concentrations of 'free' leptin in relation to fat mass and appetite in gastrointestinal cancer patients," Nutrition and Cancer, vol. 44, no. 2, pp. 156-160, 2002.

[67] M. R. Alemán, F. Santolaria, N. Batista et al., "Leptin role in advanced lung cancer. A mediator of the acute phase response or a marker of the status of nutrition?" Cytokine, vol. 19, no. 1, pp. 21-26, 2002.

[68] D. Diakowska, M. Krzystek-Korpacka, K. Markocka-Maczka, W. Diakowski, M. Matusiewicz, and K. Grabowski, "Circulating leptin and inflammatory response in esophageal cancer, esophageal cancer-related cachexia-anorexia syndrome (CAS) and non-malignant CAS of the alimentary tract," Cytokine, vol. 51, no. 2, pp. 132-137, 2010.

[69] Q. Huang, X. Zhang, Z.-W. Jiang, B.-Z. Liu, N. Li, and J.-S. Li, "Hypoleptinemia in gastric cancer patients: relation to body fat mass, insulin, and growth hormone," Journal of Parenteral and Enteral Nutrition, vol. 29, no. 4, pp. 229-235, 2005.

[70] L. Tessitore, B. Vizio, D. Pesola et al., "Adipocyte expression and circulating levels of leptin increase in both gynaecological and breast cancer patients," International Journal of Oncology, vol. 24, no. 6, pp. 1529-1535, 2004.

[71] T. Koester-Weber, J. Valtueña, C. Breidenassel et al., "Reference values for leptin, cortisol, insulin and glucose, among European adolescents and their association with adiposity: the HELENA study," Nutrición Hospitalaria, vol. 30, no. 5, pp. 1181-1190, 2014.

[72] I. Dahlman, N. Mejhert, K. Linder et al., "Adipose tissue pathways involved in weight loss of cancer cachexia," British Journal of Cancer, vol. 102, no. 10, pp. 1541-1548, 2010.

[73] D.-X. Cao, G.-H. Wu, Z.-A. Yang et al., "Role of $\beta 1$-adrenoceptor in increased lipolysis in cancer cachexia," Cancer Science, vol. 101, no. 7, pp. 1639-1645, 2010.

[74] S. D. Zuijdgeest-Van Leeuwen, J. W. O. Van Den Berg, J. L. D. Wattimena et al., "Lipolysis and lipid oxidation in weight-losing cancer patients and healthy subjects," Metabolism: Clinical and Experimental, vol. 49, no. 7, pp. 931-936, 2000.

[75] S. Klein and R. R. Wolfe, "Whole-body lipolysis and triglyceride-fatty acid cycling in cachectic patients with esophageal cancer," Journal of Clinical Investigation, vol. 86, no. 5, pp. 1403-1408, 1990.

[76] T. Agustsson, P. Wikrantz, M. Rydén, T. Brismar, and B. Isaksson, "Adipose tissue volume is decreased in recently diagnosed cancer patients with cachexia," Nutrition, vol. 28, no. 9, pp. 851855, 2012.

[77] M. Rydén, T. Agustsson, J. Andersson, J. Bolinder, E. Toft, and P. Arner, "Adipose zinc- $\alpha 2$-glycoprotein is a catabolic marker in cancer and noncancerous states," Journal of Internal Medicine, vol. 271, no. 4, pp. 414-420, 2012.

[78] M. Jeevanandam, G. D. Horowitz, S. F. Lowry, and M. F. Brennan, "Cancer cachexia and the rate of whole body lipolysis in man," Metabolism, vol. 35, no. 4, pp. 304-310, 1986.

[79] J. F. Horowitz, "Fatty acid mobilization from adipose tissue during exercise," Trends in Endocrinology and Metabolism, vol. 14, no. 8, pp. 386-392, 2003.

[80] E. C. Lin, "Glycerol utilization and its regulation in mammals," Annual Review of Biochemistry, vol. 46, pp. 765-795, 1977.

[81] N. Maeda, T. Funahashi, and I. Shimomura, "Metabolic impact of adipose and hepatic glycerol channels aquaporin 7 and aquaporin 9," Nature Clinical Practice Endocrinology and Metabolism, vol. 4, no. 11, pp. 627-634, 2008.

[82] W. Burgi and K. Schmid, "Preparation and properties of Znalpha 2-glycoprotein of normal human plasma," The Journal of Biological Chemistry, vol. 236, pp. 1066-1074, 1961.

[83] I. Díez-Itza, L. M. Sánchez, M. T. Allende, F. Vizoso, A. Ruibal, and C. López-Otín, "Zn-alpha 2-glycoprotein levels in breast cancer cytosols and correlation with clinical, histological and biochemical parameters," European Journal of Cancer, vol. 29, no. 9, pp. 1256-1260, 1993.

[84] L. P. Hale, D. T. Price, L. M. Sanchez, W. Demark-Wahnefried, and J. F. Madden, "Zinc $\alpha$-2-glycoprotein is expressed by malignant prostatic epithelium and may serve as a potential serum marker for prostate cancer," Clinical Cancer Research, vol. 7, no. 4, pp. 846-853, 2001.

[85] D. L. Albertus, C. W. Seder, G. Chen et al., "AZGP1 autoantibody predicts survival and histone deacetylase inhibitors increase expression in lung adenocarcinoma," Journal of Thoracic Oncology, vol. 3, no. 11, pp. 1236-1244, 2008. 
[86] K. Felix, F. Fakelman, D. Hartmann et al., "Identification of serum proteins involved in pancreatic cancer cachexia," Life Sciences, vol. 88, no. 5-6, pp. 218-225, 2011.

[87] Y. Bao, C. Bing, L. Hunter, J. R. Jenkins, M. Wabitsch, and P. Trayhurn, "Zinc- $\alpha$ 2-glycoprotein, a lipid mobilizing factor, is expressed and secreted by human (SGBS) adipocytes," FEBS Letters, vol. 579, no. 1, pp. 41-47, 2005.

[88] C. Bing, Y. Bao, J. Jenkins et al., "Zinc-alpha2-glycoprotein, a lipid mobilizing factor, is expressed in adipocytes and is upregulated in mice with cancer cachexia," Proceedings of the National Academy of Sciences of the United States of America, vol. 101, no. 8, pp. 2500-2505, 2004.

[89] S. T. Russell, T. P. Zimmerman, B. A. Domin, and M. J. Tisdale, "Induction of lipolysis in vitro and loss of body fat in vivo by zinc- $\alpha 2$-glycoprotein," Biochimica et Biophysica Acta, vol. 1636, no. 1, pp. 59-68, 2004.

[90] S. T. Russell and M. J. Tisdale, "Effect of eicosapentaenoic acid (EPA) on expression of a lipid mobilizing factor in adipose tissue in cancer cachexia," Prostaglandins Leukotrienes and Essential Fatty Acids, vol. 72, no. 6, pp. 409-414, 2005.

[91] S. T. Russell, K. Hirai, and M. J. Tisdale, "Role of beta3adrenergic receptors in the action of a tumour lipid mobilizing factor," British Journal of Cancer, vol. 86, no. 3, pp. 424-428, 2002.

[92] T. Mracek, N. A. Stephens, D. Gao et al., "Enhanced ZAG production by subcutaneous adipose tissue is linked to weight loss in gastrointestinal cancer patients," British Journal of Cancer, vol. 104, no. 3, pp. 441-447, 2011.

[93] F.-Y. Gong, J.-Y. Deng, H.-J. Zhu, H. Pan, L.-J. Wang, and H.-B. Yang, "Fatty acid synthase and hormone-sensitive lipase expression in liver are involved in zinc- $\alpha 2$-glycoprotein-induced body fat loss in obese mice," Chinese Medical Sciences Journal, vol. 25, no. 3, pp. 169-175, 2010.

[94] S. T. Russell and M. J. Tisdale, "The role of glucocorticoids in the induction of zinc- $\alpha 2$ - glycoprotein expression in adipose tissue in cancer cachexia," British Journal of Cancer, vol. 92, no. 5, pp. 876-881, 2005.

[95] M. L. Knapp, S. Al-Sheibani, P. G. Riches, I. W. F. Hanham, and R. H. Phillips, "Hormonal factors associated with weight loss in patients with advanced breast cancer," Annals of Clinical Biochemistry, vol. 28, no. 5, pp. 480-486, 1991.

[96] C. Bing, T. Mracek, D. Gao, and P. Trayhurn, "Zinc- $\alpha 2-$ glycoprotein: an adipokine modulator of body fat mass," International Journal of Obesity, vol. 34, no. 11, pp. 1559-1565, 2010.

[97] D. C. Y. Yeung, K. S. L. Lam, Y. Wang, A. W. K. Tso, and A. $\mathrm{Xu}$, "Serum zinc-alpha2-glycoprotein correlates with adiposity, triglycerides, and the key components of the metabolic syndrome in Chinese subjects," Journal of Clinical Endocrinology and Metabolism, vol. 94, no. 7, pp. 2531-2536, 2009.

[98] D. M. Selva, A. Lecube, C. Hernández, J. A. Baena, J. M. Fort, and R. Simó, "Lower zinc- $\alpha 2$-glycoprotein production by adipose tissue and liver in obese patients unrelated to insulin resistance," Journal of Clinical Endocrinology and Metabolism, vol. 94, no. 11, pp. 4499-4507, 2009.

[99] Y. J. Kim, K. Sertamo, M. A. Pierrard et al., "Verification of the biomarker candidates for non-small-cell lung cancer using a targeted proteomics approach," Journal of Proteome Research, vol. 14, no. 3, pp. 1412-1419, 2015.

[100] M. Gosho, K. Nagashima, and Y. Sato, "Study designs and statistical analyses for biomarker research," Sensors, vol. 12, no. 7, pp. 8966-8986, 2012. 


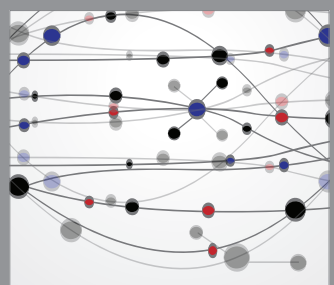

The Scientific World Journal
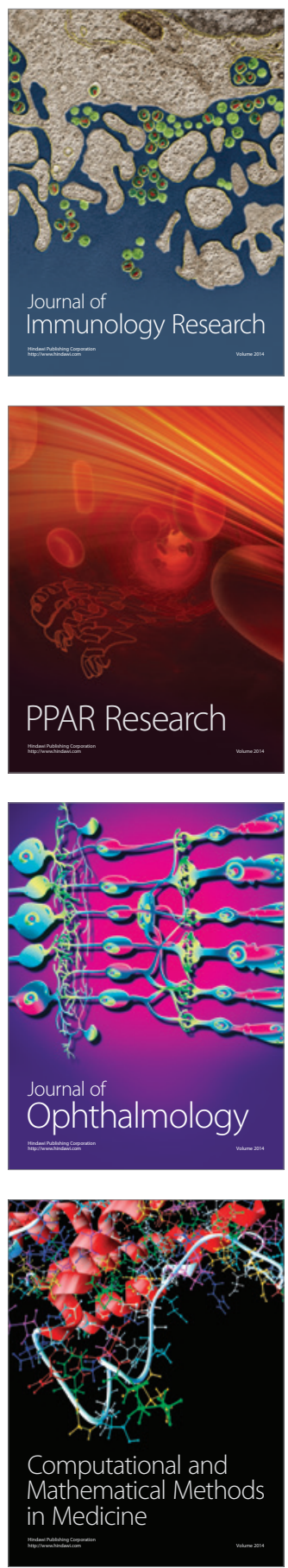

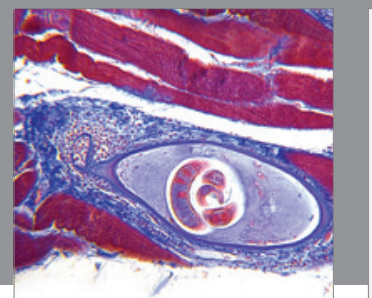

Gastroenterology

Research and Practice
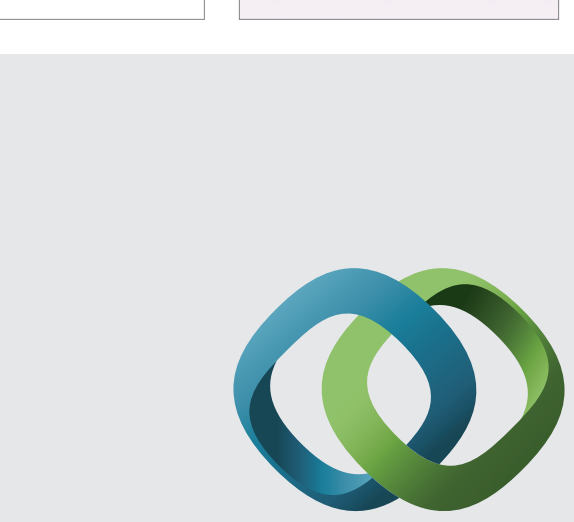

\section{Hindawi}

Submit your manuscripts at

http://www.hindawi.com
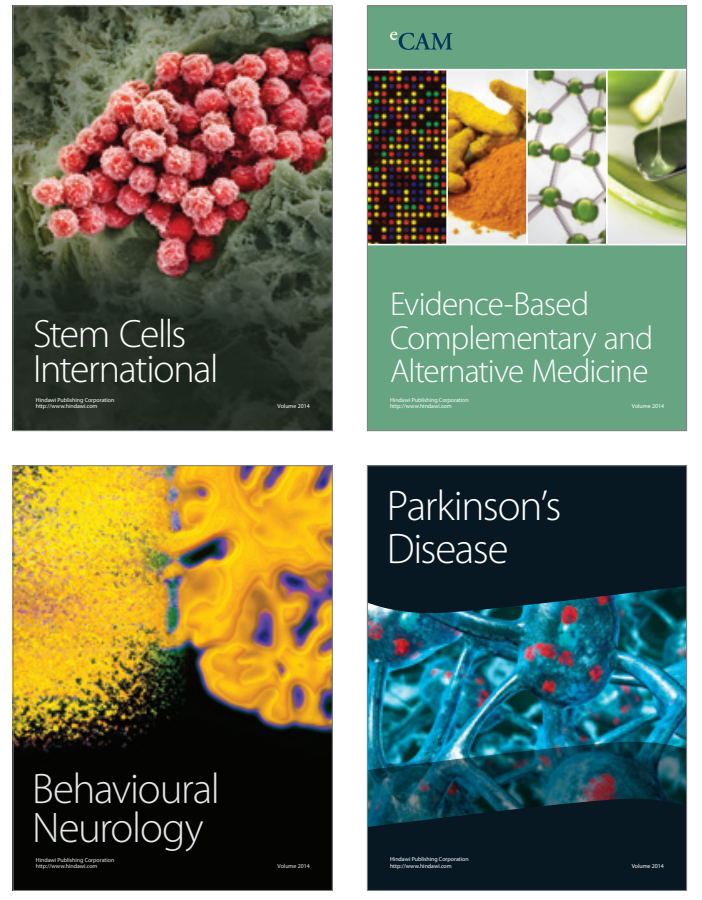
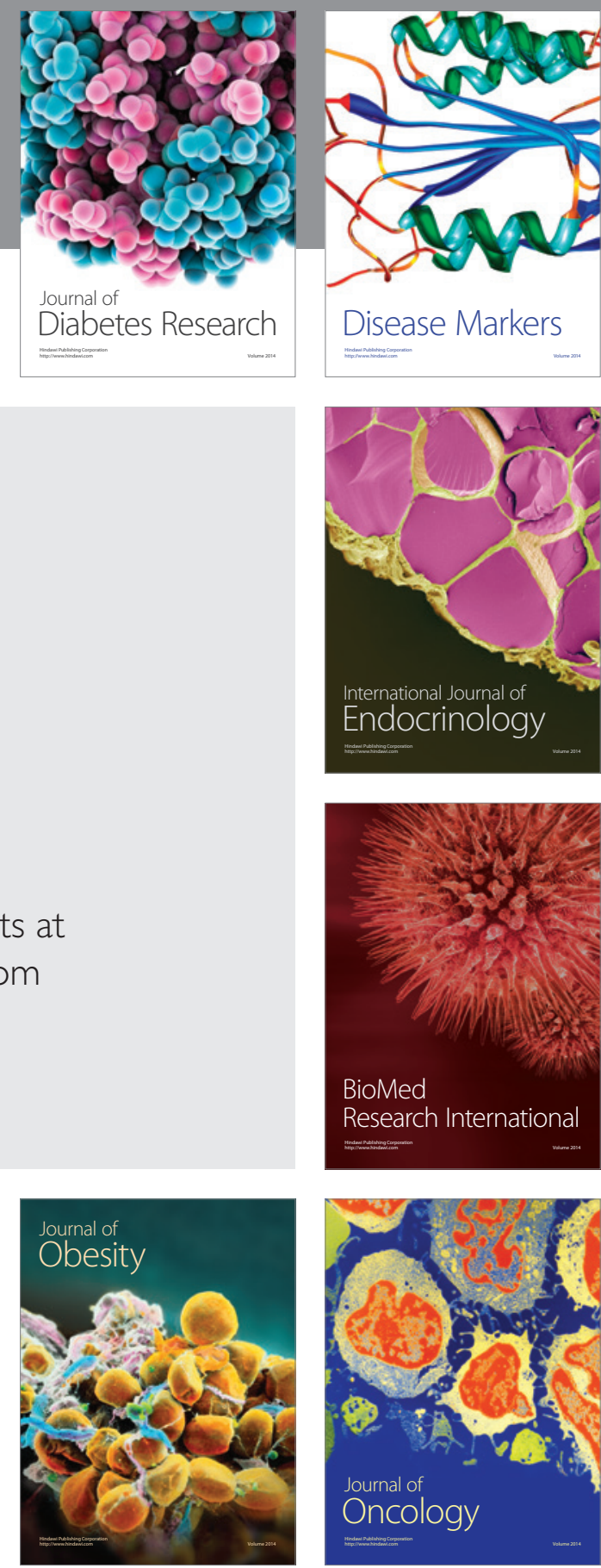

Disease Markers
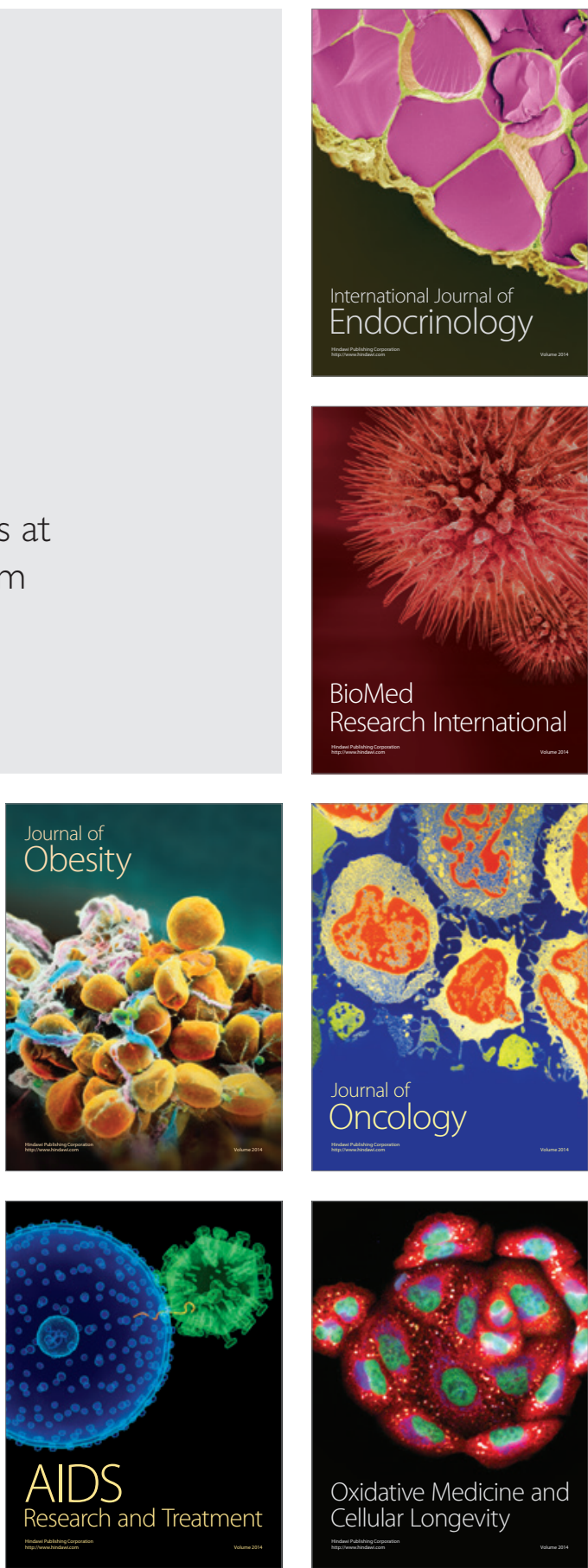